\title{
Do feminismo aos estudos de gênero no Brasil: um exemplo pessoal ${ }^{*}$
}

\author{
Mariza Corrêa**
}

\section{1. percurso}

O movimento feminista no Brasil contemporâneo ${ }^{1}$, que teve sua maior expressão na década de 1970, esteve intimamente articulado com outros movimentos sociais da época: movimentos populares - que iam desde a luta por moradia, passando por melhores condições de vida (água encanada, luz, transporte), até a luta pela criação de creches nas fábricas e universidades (o que

\footnotetext{
* Recebido para publicação em outubro de 2001. Esta é uma avaliação muito parcial do feminismo no Brasil, contada desde a perspectiva de minha participação, para uma platéia estrangeira, os alunos do Programa de Estudos sobre as Mulheres da Universidade Aberta de Lisboa. Agradeço a acolhida amável e generosa de Teresa Joaquim e suas colegas e a calorosa discussão sobre este texto em fevereiro deste ano. Não me arriscaria a fazer uma avaliação semelhante do campo do feminismo hoje no país, por sua enorme diversidade e o espantoso crescimento de centros e publicações regionais; um bom índice das tendências contemporâneas pode, entretanto, ser a leitura das coleções das duas principais revistas publicadas no país, a Revista de Estudos Feministas, que começou a ser publicada no Rio de Janeiro, em 1992, e hoje está sediada na Universidade de Santa Catarina, e Cadernos Pagu, publicada desde 1993 pelo Pagu/Núcleo de Estudos de Gênero da Unicamp. Mas creio que várias das observações que faço a seguir se aplicariam, mutatis mutandis, ao grupo que criou a $R E F$, bem como ao grupo de pesquisadoras da Fundação Carlos Chagas.

** Professora do Departamento de Antropologia do IFCH/Unicamp e pesquisadora do Núcleo de Estudos de Gênero - Pagu.

${ }^{1}$ Falo aqui em Brasil contemporâneo porque houve outros movimentos e outros jornais feministas no Brasil, desde o início do século passado: ver SAFFIOTI, Heleieth. A mulher na sociedade de classes:mito e realidade. São Paulo, Editora Quatro Artes, 1969.
} 
Do feminismo aos estudos de gênero

era uma lei antiga, mas não cumprida); movimentos políticos - aí incluídos os movimentos pela anistia aos presos políticos, pela luta contra o racismo, pelos direitos à terra dos grupos indígenas do país e o movimento dos homossexuais. Tudo isto está bem documentado numa série de artigos, livros e teses e não vou me estender muito sobre esse contexto. ${ }^{2}$ Apenas começo por ele porque creio que é importante lembrar que no início dos anos setenta estávamos nos piores anos da ditadura militar que assumiu o governo do país em 1964: havia uma dura repressão às lutas da esquerda contra o regime - a tortura $e$ a morte de militantes ou simpatizantes dos militantes eram uma presença constante na nossa vida cotidiana apesar, ou por causa, de sua ausência nos jornais - e um esvaziamento dos canais políticos tradicionais, com a censura aos jornais, a dissolução dos partidos políticos existentes $e$ a permanente ameaça de cassação dos direitos políticos daqueles que ainda estavam atuando no cenário partidário. A instituição, se não a única (o Partido Comunista em suas duas versões sendo outra), a mais importante, que se mantinha íntegra era a Igreja $e$ foi a partir de pequenas lutas encorajadas ou apoiadas por ambos que esses movimentos sociais começaram a se articular. No caso do movimento feminista não foi diferente: várias das iniciativas mais organizadas do movimento estavam vinculadas à Igreja ou ao Partido - embora houvesse um permanente ponto de fricção nessa aliança com a Igreja, que era a defesa do aborto feita pelas feministas. Também havia fricções com os militantes comunistas, mas por outras razões: no caso deles tratava-se de dar prioridade à "luta mais ampla" em detrimento das reivindicações feministas e o ataque à participação

2 Para uma avaliação desses movimentos e bibliografia, ver CARDOSO, Ruth. Movimentos sociais urbanos: um balanço crítico. In: ALMEIDA, Maria Herminia T. de e SoRJ, Bernardo. (orgs.) Sociedade e política no Brasil pós-64. São Paulo, Editora Brasiliense, 1983. 
de lésbicas no movimento foi uma das táticas utilizadas para tentar impedir a realização de um congresso feminista, por exemplo. ${ }^{3}$

É difícil traçar um perfil mais específico das feministas daquela época, já que elas eram atrizes de teatro - lembrar a atriz portuguesa radicada no Brasil, Ruth Escobar, por exemplo, que transformou seu teatro num importante local de discussão sobre a situação da mulher -, professoras universitárias, estudantes, sindicalistas, ativistas vindas de movimentos populares, jornalistas, etc. Creio que havia um traço comum à todas, pelo menos em São Paulo e no Rio, que foi onde circulei mais durante aqueles anos: eram mulheres de esquerda e eram mulheres profissionais ou em vias de se tornarem profissionais. Minha própria caracterização - aluna de pós-graduação de uma universidade paulista, escrevendo uma tese sobre os "crimes passionais" - me levou a conviver mais estreitamente com os grupos de pesquisadoras, sobre os quais vou falar em seguida.

Mas foi uma característica anterior, o fato de ter sido jornalista, que me levou a conhecer o grupo de mulheres envolvidas com a criação de um jornal feminista: o Nós Mulheres. ${ }^{4}$ Tinha terminado de defender minha dissertação de mestrado ${ }^{5} e$

3 Ver Maria Amélia de Almeida Teles, citada abaixo, para a descrição do episódio. Ver também MACRAE, E. Os respeitáveis militantes e as bichas loucas. (In: Caminhos cruzados. Linguagem, Antropologia e Ciências Naturais. São Paulo, Editora Brasiliense, 1982.), para as difíceis relações entre os integrantes do movimento de homossexuais e os socialistas. Edward faz também um interessante comentário sobre a noção de "camp" de Susan Sontag que pode servir como pista para pensar nas relações, difíceis então, e até hoje, entre gays e feministas e seus colegas profissionais, seja qual for o seu campo de ação, e incluído aí o campo das ciências sociais: "A força do 'camp' repousa em grande parte no seu humor corrosivo e iconoclasta, disposto a ridicularizar todos $e$ quaisquer valores".

4 O Brasil Mulher, editado por Joana Lopes, primeiro em Londrina e depois em São Paulo, era um pouco anterior ao Nós Mulheres. Publicado entre 1975 e 1979 era, de início, um veículo para promover a anistia no país.

5 Publicada em 1983: Morte em familia. Representaçóes jurídicas de papéis sexuais. Rio de Janeiro, Edições Graal. A questão só se tornaria relevante para o movimento feminista e a mídia nos anos oitenta. 
Do feminismo aos estudos de gênero

estava desempregada quando soube, por um amigo jornalista de minha terra ${ }^{6}$, Marcos Faermann, que na mesma casa onde ele e outros colegas de esquerda estavam produzindo uma revista cultural de resistência à ditadura, como se dizia na época, a revista Versus, e talvez não por acaso no porão, havia um grupo de mulheres se reunindo para produzir um jornal feminista. Era o ano de 1975. Era também, por decisão da ONU, o Ano Internacional da Mulher. E foi nesse ano que a polícia política matou o jornalista Wladimir Herzog na cadeia, evento que desencadeou protestos até no interior do governo militar e que levou Michel Foucault, que dava uma série de palestras na Universidade de São Paulo, a interromper seu trabalho - com uma nota em que falava da impossibilidade de se fazer uma discussão livre sob o tacão das botas da ditadura - e a aceitar um convite dos estudantes da Unicamp para falar no seu Centro Acadêmico. ${ }^{7} \mathrm{E}$ creio que foi neste mesmo ano, ou um pouco depois, que a rede Globo de televisão lançou um seriado que teve grande repercussão, o Malu Mulher. estrelado por Regina Duarte, expunha na tela, com uma linguagem acessível, várias das questões que eram discutidas nos centenas de grupos de mulheres que foram criados no país nessa época.

Esses grupos recém criados eram, é claro, tão atravessados por dissensões políticas quanto quaisquer outros: ainda que a imprensa homogeneizasse o movimento, falando sobre as

${ }^{6}$ Creio que meu percurso profissional foi semelhante ao de muitas mulheres de minha geração: depois de cursar a Escola Normal, fui uma das apenas duas moças de minha turma que ingressaram na Universidade. Fiz o curso de jornalismo e trabalhei em jornais - um jornal gaúcho, primeiro (Zero Hora), um jornal mineiro depois (Diário de Minas), e fui selecionada, num concurso nacional, para integrar a equipe que produziu a primeira revista semanal do país, em 1967, a revista Veja, da editora Abril, publicada em São Paulo.

7 Foucault teve um grande impacto teórico sobre os pesquisadores brasileiros desde aquela visita e provocou também grande impacto em Dona Lola, empregada doméstica de minha casa, uma senhora negra, ao levantar-se cortesmente da almofada em que estava sentado, à sua passagem... 
feministas 8 , éramos de fato grupos com lealdades muito diversificadas - em relação à Igreja, ao Partido Comunista, ou à Universidade. Assim, uma das questões que reiteradamente aparecia nas nossas discussões era a clivagem entre militantes e pesquisadoras, clivagem que se tornou importante à medida que a pesquisa sobre a situação da mulher no país ganhou preeminência sobre os movimentos de mulheres. ${ }^{9}$

O jornal Nós Mulheres ${ }^{10}$, cujo primeiro número foi lançado em junho de 1976, não conseguiu sobreviver muito tempo: era

\footnotetext{
${ }^{8}$ Lembro de um cartum de Millor Fernandes que apareceu por esta época e que mostrava as garras, com unhas pintadas, de um Tio Sam feminino manipulando uma marionete simbolizando as feministas brasileiras... Millor não estava inteiramente equivocado ao vincular o feminismo brasileiro à política norteamericana: embora a maioria das mulheres que se tornaram feministas nessa geração tenham passado antes pela França do que pelos Estados Unidos no início dos anos setenta (o que era o meu caso e o de algumas das pesquisadoras da Fundação Carlos Chagas), as verbas de pesquisa para estudar a situação das mulheres viria principalmente de fundações norte-americanas. Ver MICELI, Sergio. (org.) A Fundação Ford no Brasil. São Paulo, Editora Sumaré/Fapesp, 1993: as verbas destinadas à Fundação Carlos Chagas, nas rubricas Women's studies e Educação, estão em segundo lugar nas dotações da Ford entre 1962 e 1992, só um pouco abaixo das concedidas à Universidade Católica do Rio de Janeiro - e um pouco acima do concedido ao CEBRAP - Centro Brasileiro de Análise e Planejamento, de São Paulo, comumente apontado como seu maior "cliente". Elas representam também quase o dobro do que foi concedido aos estudos de relações raciais, no Centro de Estudos Afro-Asiáticos.

9 Para uma avaliação do feminismo contemporâneo no Brasil com ênfase na militância, ver TELES, Maria Amélia de Almeida. Breve história do feminismo no Brasil. São Paulo, Editora Brasiliense, 1999; para outra, com ênfase na pesquisa, ver HEILBORN, Maria Luiza e SoRJ, Bila. Estudos de gênero no Brasil, e o comentário de GREGoRI, Maria Filomena. Estudos de gênero no Brasil (comentário crítico), ambos em MicELI, Sergio. (org.) O que ler na ciência social brasileira (1970-1995). Sociologia (volume II), São Paulo, Editora Sumaré/ANPOCS, Brasília, Capes, 1999.

${ }^{10}$ Fui a jornalista responsável pela publicação, pois era a única das mulheres que possuía registro como jornalista profissional mas, de fato, fazíamos um trabalho coletivo. As matérias não eram assinadas e sua publicação era sempre precedida de uma discussão geral, em que todas davam palpites sobre a sua forma final. $\mathrm{O}$ jornal deixou de circular em 1978.
} 
Do feminismo aos estudos de gênero

feito numa base de trabalho voluntário e coletivo, quase uma utopia, $e$ as participantes acabaram se dispersando por outros grupos, mas algumas das mulheres que participaram de sua feitura continuaram a se encontrar, agora em outras instituições. A mais importante delas em São Paulo, a Fundação Carlos Chagas, tinha uma grande concentração de profissionais preocupadas com a situação da mulher, reunidas no Departamento de Pesquisas Educacionais sob a direção da psicóloga Carmen Barroso, já autora de alguns textos sobre o assunto, e lá se constituiu, com o apoio da Fundação Ford, um importante núcleo aglutinador de pesquisadoras e feministas. O primeiro concurso, que oferecia bolsas para pesquisar a situação da mulher no país, foi realizado em âmbito nacional em 1978 e continua a existir até hoje, agora com o apoio da Fundação MacArthur, e dirigido desde há alguns anos para o tema da saúde reprodutiva. ${ }^{11}$ Três anos depois de lançado o Concurso, a Fundação investiu também na criação de mais um jornal feminista, o jornal Mulherio ${ }^{12}$ : feito em bases mais profissionais do que os anteriores, tinha uma equipe técnica e as matérias eram assinadas. Em alguns casos os nomes do Conselho

${ }^{11}$ A Fundação programou um seminário, para o mês de março deste ano, em comemoração aos mais de vinte anos da existência do Concurso de Pesquisa ao qual estarão presentes muitas das personagens responsáveis pela sua criação. $\mathrm{O}$ título do seminário sinaliza a mudança no rumo das pesquisas que estou tentando analisar aqui: Estudos de Gênero Face aos Dilemas da Sociedade Brasileira. Além de ter publicado a importante obra de referência. Mulher Brasileira. Bibliografia Anotada (2 volumes, São Paulo, Editora Brasiliense, 1979, 1981), a Fundação publicou também várias coletâneas com seleções dos trabalhos de pesquisa financiados ao longo desses anos. A Fundação é estatal, vinculada à Secretaria de Cultura, Ciência e Tecnologia do Estado de São Paulo. [Quando escrevi esta nota não sabia que o seminário marcaria também o encerramento dessa fase dos concursos da Fundação. Os trabalhos de balanço sobre esses anos todos, lá apresentados, ao serem publicados certamente contribuirão para aprofundar esta breve história.]

${ }^{12}$ Mulherio também contava com o apoio da Fundação Ford e foi publicado entre 1981 e 1987. Fez, de início, grande sucesso, contando com cerca de mil assinantes já em seu terceiro número, mas também não conseguiu se manter, como a maior parte das publicações alternativas da época. 
Editorial repetiam os nomes do Conselho do Nós Mulheres. ${ }^{13}$ Mas não todos: muitas das mulheres que participaram da criação do primeiro jornal estavam agora, apenas seis anos depois, integrando os quadros dos novos partidos políticos, criados com a "abertura" de 1979, e eram assunto das matérias do jornal. ${ }^{14}$ Outras estavam nas cada vez mais numerosas Organizações Não Governamentais, também criadas a partir da redemocratização do país, ou nas agências do governo, que também se multiplicaram desde então: os conselhos estaduais da condição feminina $e$ o Conselho Nacional dos Direitos da Mulher, por exemplo. ${ }^{15} \mathrm{E}$ um número grande delas tinha ido para a Universidade.

${ }^{13}$ O Conselho era formado por Carmen Barroso, Carmen da Silva, Cristina Bruschini, Elizabeth Souza Lobo, Eva Alterman Blay, Fúlvia Rosemberg, Heleieth Saffioti, Lélia Gonzalez, Maria Carneiro da Cunha, Maria Malta Campos, Maria Moraes, Maria Rita Kehl, Maria Valéria Junho Pena, Marilia de Andrade, Mariza Corrêa e Ruth Cardoso.

${ }^{14} 1979$ foi o ano da anistia e do I Congresso da Mulher Paulista, que contou com cerca de 900 participantes no Teatro Ruth Escobar. O país vivia um clima de euforia, com o retorno de muitos exilados e da recriação dos canais políticos institucionalizados o que permitiu um encontro festivo, no qual as diferenças políticas não pareciam tão importantes. No II Congresso, no ano seguinte, que contou com a participação de cerca de quatro mil mulheres, as várias facções políticas presentes entraram em conflito, já anunciando a divisão que ocorreria no III Congresso, em 1981, quando as militantes comunistas criaram a Federação das Mulheres do Brasil, provocando uma divisão do movimento. Ver TELES, M. A. de A. Breve história do feminismo... Op.cit. A partir daí, muitas das feministas mais antigas passaram a uma militância mais discreta, em ONGs, núcleos de estudos, partidos políticos ou agências governamentais.

${ }^{15} \mathrm{O}$ Estado de São Paulo deu o exemplo, seguido depois por quase todos os estados, na criação dessas agências na década de oitenta, criando, em 1983 o Conselho Estadual da Condição Feminina e, em 1985, a Delegacia de Defesa dos Direitos da Mulher. O Conselho Nacional foi criado em 1985, pelo governo federal. Em 1986, na eleição para o Congresso Constituinte foram eleitas 26 mulheres. Ver TELES, M. A. de A. Breve história do feminismo... Op.cit. 
Do feminismo aos estudos de gênero

\section{2. pesquisas}

A mesma euforia participativa que estava nas ruas no final dos anos setenta, estava também na universidade. Em 1976 fui trabalhar na Universidade Estadual de Campinas, então recém fundada e com um corpo docente predominantemente jovem e de esquerda - de fato, vários docentes lá contratados tinham tido um passado político de envolvimento com partidos então ilegais ou com movimentos estudantis na década anterior, e não poucos foram presos uma vez ou outra. E muitos deles voltavam de uma estadia no exterior - ou forçada ou para escapar aos maus ventos que sopravam no país. O contexto era assim favorável à discussão dos movimentos sociais que estavam presentes na sociedade mais abrangente e à discussão de idéias democráticas dentro das salas de aula. Foi nesse contexto que um grupo de alunas e professoras da área de Ciências Sociais criou um grupo de reflexão feminista, organizou três Semanas da Mulher, em 1978, 1979 e 1980, e partiu para a pesquisa com mulheres. ${ }^{16}$ Outros professores $e$ alunos participavam do movimento de homossexuais - tanto de um dos seus grupos mais importantes, o grupo Somos, quanto da fundação do pioneiro jornal gay Lampião de esquina, ambos criados em São Paulo em 1978. ${ }^{17}$ Campinas era, então, uma cidade de médio porte, com poucos cinemas e livrarias, professores $e$ alunos tinham quase a mesma idade $e$ o divertimento mais comum eram almoços e jantares nas casas uns

\footnotetext{
${ }^{16}$ Nosso grupo se chamou, primeiro, mais seriamente "Coletivo Feminista" nome inventado às pressas por Verena Stolcke e por mim, às vésperas de um debate já não lembro mais para que órgão da imprensa que, na época, estava muito interessada nas atividades feministas e, depois, de brincadeira, "Grupo Oito e meio" - porque éramos oito mulheres e um homem que pesquisava a literatura feminina no século 19.

${ }^{17}$ Ver FRY, Peter. Para inglês ver. Identidade e política na cultura brasileira. Rio de Janeiro, Zahar editores, 1982; MACRAE, Edward. A construção da igualdade: identidade sexual e política no Brasil da "abertura". Campinas, Editora da Unicamp, 1990; GREEN, James N. Além do carnaval. A homossexualidade masculina no Brasil do século XX. São Paulo, Editora da UNESP, 2000.
} 
dos outros que frequentemente terminavam em sessões dançantes improvisadas - uma das Semanas da Mulher encerrou-se com a festa "Teoria \& Prática" e um dos vários buttons que aqui chegavam na época dizia "If I can't dance I do not want to be part of your revolution" - Emma Goldman.

Cabe também lembrar um ângulo cultural frequentemente esquecido nessas avaliações dos anos setenta: a música e o teatro, à falta de outros canais de articulação política, foram extremamente importantes como catalizadores da opinião pública: o grupo teatral Dzi Croquettes, objeto de tese de uma aluna da pós-graduação da Unicamp ${ }^{18}$, e o cantor Ney Matogrosso, expunham no palco, com muito mais picardia que as discussões teóricas atuais, a relação entre sexo e gênero e a temática, só recentemente transformada em questão teórica, do uso performático do corpo.

Creio que esse diálogo entre feministas e homossexuais, bastante singular na época ${ }^{19}$, tenha sido crucial para a boa receptividade, anos mais tarde, dos estudos de gênero por pesquisadoras dessa universidade: ainda que os estudos feministas tenham sido o campo de estudos de todas as pesquisadoras que hoje participam do Núcleo de Estudos de Gênero/Pagu, certamente pesquisas como as de Peter Fry e Néstor Perlongher ${ }^{20}$ foram importantes para tornar mais complexas as distinções polarizadas, e então comuns, do masculino/feminina, já nos anos setenta. Ou, para dizê-lo numa formulação mais precisa, a combinação da influência predominante na antropologia de

\footnotetext{
${ }^{18}$ LOBERT, Rosemary. A palavra mágica Dzi: uma resposta difícil de se perguntar. Campinas, dissertação de mestrado da Unicamp, 1979.

${ }^{19}$ Lembro o episódio mencionado antes, de acusações de alguns grupos comunistas às lésbicas, em 1981, e da declaração de uma lésbica militante que participou de uma das Semanas da Mulher em Campinas: "Essa discussão não seria possível em São Paulo". A província tinha algumas vantagens...

${ }^{20}$ Perlongher, Nestor. O negócio do michê. Prostituição viril em São Paulo. São Paulo, Editora Brasiliense, 1987, originalmente uma dissertação de mestrado da Unicamp.
} 
Do feminismo aos estudos de gênero

Campinas, a da escola britânica, com a influência teórica de Michel Foucault naqueles anos, aliada ao debate constante com o incipiente campo de estudos que hoje se convenciona chamar de queer's studies, foi importante para desnaturalizar aquela distinção polarizada e seus termos. O que é interessante é que nos cursos que oferecíamos aos nossos alunos sobre sexualidade, ou papéis sexuais, o famoso "caso Agnes" era leitura obrigatória. Agnes era um menino que decidiu "tornar-se mulher" $e$ que parece representar no universo psicanalítico do século XX um papel equivalente ao que teve Anna O. no século XIX: o de catalizadora de um conceito que "estava no ar", neste caso, o de gênero. ${ }^{21}$ É interessante, também, que, era comum dizermos pelos corredores, ou para nossos alunos, "A mulher não existe", inspiradas pelo texto de Paul Veyne, "Foucault revoluciona a história" - mas quando escrevíamos, adotávamos a moeda corrente da época nos estudos feministas: caso típico de termos de "aprender a pensar o que sabíamos". ${ }^{22}$

Foi só recentemente que reconstruí essa história vivida nos primeiros anos da vida profissional: ao ler o artigo de Maria Luiza Heilborn, fazendo um balanço das pesquisas sobre feminismo no Brasil, me dei conta de que os primeiros nomes que ela cita são de

${ }^{21} \mathrm{O}$ caso é analisado num artigo de Harold Garfinkel em colaboração com Robert J. Stoller, o psicanalista que generalizou as pesquisas do Gender Identity Research Project na Universidade da Califórnia e apresentou o termo ao Congresso Internacional de Psicanálise, em Estocolmo, em 1963. Ver Passing and the managed achievement of sex-status in "intersexed" persons-Part 1. In: GARFinKEL, H. Studies in Ethnomethodology. N.Y., Prentice Hall, 1967.

${ }^{22}$ Não lembro o autor da frase, mas ela foi dita por um intelectual brasileiro ao relembrar a importação de intelectuais franceses e norte-americanos para São Paulo, quando da criação de duas importantes instituições do ensino das Ciências Sociais na década de trinta: a escola Livre de Sociologia e Política e a Faculdade de Filosofia da Universidade de São Paulo. O que sabíamos começava a aparecer, timidamente, na coletânea que organizei, com trabalhos de colegas do departamento, Colcha de retalhos. Estudos sobre a família no Brasil. São Paulo, Editora Brasiliense, 1982. Ver especialmente a ênfase na pluralidade, presente no artigo de Suely Kofes e no meu. 
quatro professoras do departamento de antropologia da Unicamp, duas delas então alunas, e presentes nas fotografias esmaecidas que guardamos das Semanas da Mulher. ${ }^{23}$ Minha trajetória particular nesse percurso do feminismo aos estudos de gênero só ganha sentido, assim, se avaliada num contexto mais geral no qual a articulação entre militância política, pesquisa acadêmica $e$ cenário político-cultural sejam levados em conta. ${ }^{24} \mathrm{E}$ talvez seja

${ }^{23} \mathrm{O}$ artigo de HeILBORN, Maria Luiza. Fazendo gênero? A antropologia da mulher no Brasil, está em CosTA, Albertina de Oliveira e BRUSCHINI, Cristina. (orgs.) Uma questão de gênero. Rio de Janeiro/São Paulo, Rosa dos Tempos/Fundação Carlos Chagas, 1992. As professoras somos Guita Green Debert e eu; as, então, alunas, Heloisa Pontes e Maria Filomena Gregori - todas hoje parte do grupo de pesquisadoras do Pagu e da área "Família e Gênero" do Doutorado em Ciências Sociais da Unicamp. Elizabeth Souza Lobo, uma das integrantes do grupo que fazia o jornal Mulherio, foi, juntamente com Adriana Piscitelli, então aluna de nosso doutorado, a grande estimuladora da criação do Pagu, em 1993. Maria Moraes, a quem conheci naquele ano de 1975, como parte do grupo que fazia o Nós Mulheres, hoje professora do Departamento de Sociologia, também se integrou ao núcleo. O núcleo, é claro, congrega muitas outras pesquisadoras - o que estou enfatizando aqui é uma certa continuidade histórica entre o feminismo da década de setenta e o campo de estudos de gênero, isto é, a mostrar que alguns dos agentes que estiveram envolvidos com as lutas feministas/gay da época foram também importantes para a constituição desse novo campo. Não por acaso, a secretária de redação do Cadernos Pagu, e pesquisadora do núcleo, Iara Beleli, era parte daqueles primeiros grupos de estudantes que organizaram os grupos de estudos $e$ as semanas da mulher, bem como Ângela Carneiro Araújo, organizadora do dossiê a ser publicado no próximo volume dos Cadernos. Margaret Lopes, atual coordenadora do núcleo, integrou o importante centro de documentação feminista, CIM (Centro de Informação Mulher), em São Paulo, desde o seu início.

${ }^{24}$ Seria preciso prestar atenção, particularmente, à produção de programas da tevê Globo nesses anos. Lembrei o exemplo de Malu mulher, mas houve também dois outros seriados importantes para o arejamento das questões tratadas pelas feministas: o programa Quem ama não mata, creio que na década de oitenta, quando alguns crimes rumorosos de assassinato de mulheres chamaram a atenção da opinião pública (fazendo com que minha tese de mestrado que, ironicamente, era então mais lida por juristas, passasse a interessar também a feministas...) e outro sobre as delegacias da mulher, então recém criadas. 
Do feminismo aos estudos de gênero

bom lembrar, como antídoto às revisões históricas que acreditam numa imersão suave das feministas no meio acadêmico brasileiro, o mal estar que, ainda hoje, gera o interesse de pesquisa centrado nas mulheres. Lembro do comentário de um renomado antropólogo brasileiro ao assistir ao meu vídeo de pesquisa sobre a história da antropologia: "Interessante, mas tem muita mulher..." 25

\section{3. problemas}

O primeiro problema sobre o qual gostaria de chamar a atenção nessa relação entre feminismo e gênero diz respeito à clivagem antes mencionada entre militantes e pesquisadoras $e$ tem, claro, a ver com meu interesse pela história: relendo os artigos produzidos nesses últimos anos sobre o movimento feminista e as questões de gênero no Brasil, fico surpreeendida, embora não o devesse, com o quanto a participação de cada autora num certo contexto direciona também sua análise. Isto é também uma nota de cautela sobre a minha própria leitura da questão - que deve ter também seus vieses... Mas creio que o ponto importante a enfatizar aqui é a necessidade de se contextualizar adequadamente a história do feminismo, sem perder de vista a importância do contexto político e cultural à época de sua emergência, nem deixar de lado agentes que pelo fato de não estarem presentes nos estudos de gênero hoje, nem por isso deixaram de ter sua importância nessa história. Como disse antes, creio que há uma clara articulação entre o feminismo dos anos setenta e a emergência dos estudos de gênero nos anos noventa, assim como acredito que houve uma estreita vinculação entre as chamadas militantes e as pesquisadoras, naquela época,

${ }^{25}$ Trata-se do vídeo Cem anos de antropologia. Imagens brasileiras, realizado em parceira com Angela Galrão em 1994, e parte de minha pesquisa Antropólogas \& Antropologia. O vídeo apresenta cerca de trinta personagens masculinos e cerca de vinte personagens femininas - e certamente não é exaustivo. 
mas aqui não tenho todos os dados para provar essa afirmação de maneira bem acabada. ${ }^{26}$

Isso não implica em negar a existência de pesquisadores não envolvidos com a militância hoje, mas implica sim em enfatizar a impossibilidade da existência de estudos de gênero que não tenham uma dimensão política, parte de sua história.

O segundo problema é a imensa lacuna bibliográfica na já mencionada relação entre raça e gênero: se o feminismo nos permitiu lutar, num primeiro momento, para a constituição de um sujeito Mulher, assim mesmo com letra maiúscula, o próprio desenvolvimento dos movimentos feministas foi, aos poucos, desinvestindo esse sujeito do lugar central que lhe dávamos nos anos setenta, desqualificando sua singularidade, questionando sua identidade e universalidade. ${ }^{27}$ É claro que em relação à questão

${ }^{26} \mathrm{O}$ ponto é importante porque na visão maniqueísta que separa militantes $e$ pesquisadoras naquele momento, perde-se de vista que nós, pesquisadoras, éramos também militantes e que, se nos desiludimos com algumas das crenças inscritas em nossas palavras de ordem, não foi porque nosso "compromisso maior era com o fazer ciência social" (HEILBORN, Maria Luiza e SoRJ, Bila. Estudos de gênero no Brasil... Op.cit.), mas sim porque nosso compromisso maior era com a tentativa de compreender a sociedade brasileira, para mudá-la. Seria também preciso recuperar a história das pesquisadoras pioneiras do campo feminista e as dificuldades de sua intromissão no campo das ciências sociais na época, para relembrar o quão pouco convencionais eram essas relações, isto é, quão pouco essas pesquisadoras obedeciam às convenções do campo das ciências sociais na sua atuação cotidiana... Neste sentido, não posso concordar com a afirmativa de Heilborn e Sorj de que "a área de estudos de gênero... prescinde das motivações políticas que marcaram sua origem $e$ a primeira geração de pesquisadoras." Nenhum campo intelectual pode prescindir de sua própria história.

${ }^{27}$ No exemplo de minhas pesquisas, lembro que em 1974 publiquei uma peça panfletária contra um dos pais da antropologia inglesa (Antropologia $e$ colonialismo cultural: o professor Evans-Pritchard e a mulher) num newsletter produzido por um departamento marcado pela influência inglesa - e que, se escândalo houve, era devido à iconoclastia acadêmica - mas não à ênfase universalizante atribuída às mulheres, e que o subtítulo de minha tese de mestrado falava em 'papéis sexuais', hoje uma das noções anátemas para a teoria feminista. (Retomei o contexto de Evans-Pritchard numa peça mais 
Do feminismo aos estudos de gênero

racial havia uma cegueira estrutural na sociedade brasileira, e a relação "raça e gênero" só começa a se tornar teoricamente relevante a partir da leitura dos textos de autoras norteamericanas, elas sim questionadas pelo feminismo das mulheres negras. ${ }^{28}$

fundamentada em $\mathrm{O}$ espartilho de minha avó: linhagens femininas na antropologia. Horizontes Antropológicos (7), 1997.

Este movimento de desqualificação do sujeito é, é claro, muito mais amplo e teve repercussão não apenas nas discussões filosóficas do final do século vinte, como encontrou eco também nas ciências sociais, particularmente na antropologia.

${ }^{28}$ Lembro de uma festa de inauguração, não tão distante assim no tempo, de alguma agência feminista em São Paulo, cujas fotos, publicadas nos jornais, mostravam as feministas cercadas por empregadas domésticas, de uniforme engomado, negras ou mulatas. Convém lembrar, no entanto, que a luta contra o racismo era um dos pontos importantes da agenda política do feminismo nos anos setenta - ver no primeiro número de Nós Mulheres o depoimento de uma mulher negra e lembrar que o Conselho de Mulherio também contava com uma militante do Movimento Negro, Lélia Gonzales. A questão racial era parte importante das discussões da época no nosso Departamento de Antropologia: pelo menos duas teses nas quais a questão racial é central foram defendidas por docentes brasileiras - a dissertação de mestrado de Suely Kofes - integrante do grupo inicial que criou o Pagu - e a minha tese de doutorado (As ilusóes da liberdade. A Escola Nina Rodrigues e a antropologia no Brasil, Bragança Paulista, EDUSF, 1998). A questão racial era também central para a tese de doutorado de Verena (Martinez-Alier)Stolcke (Marriage, class and colour in nineteenth century Cuba. A study of racial attitudes and sexual values in a slave society. Ann Arbor, The University of Michigan Press, 1989, originalmente, 1974), que orientou as teses de mestrado de Suely e a minha, e para a de Peter Fry ( Spirits of protest:spirit mediuns and the articulation of consensus amongst the Zezuru of Southern Rhodesia (Zimbabwe). Cambridge, Cambridge University Press, 1976), que trabalha com a questão até hoje. Verena participou também, antes de sair do Brasil, dos grupos de estudo e das semanas mencionados.

Sobre a importância das feministas negras no cenário americano, e as consequências téoricas de sua participação no debate, ver HARAWAY, Donna. "Gender" for a Marxist dictionary: the sexual politics of a word. In: Simians, Cyborgs and Women. The reinvention of nature. N.Y., Routledge, 1991; e, para o debate brasileiro, Cadernos Pagu (6/7), 1996. Não me arrisco a fazer observações sobre a trajetória do feminismo no movimento negro, apenas registro que o interesse pela pesquisa nessa área vem crescendo nos últimos anos, conforme posso observar na minha universidade e pude verificar num 
Vejo, assim, a noção de gênero quase como uma saída lógica de um impasse linguístico/político contra o qual já nos alertava Simone de Beauvoir com sua famosa frase de abertura de O Segundo Sexo: "Não se nasce mulher..." Postos dessa maneira, a emergência e o uso dessa noção, levam também quase inevitavelmente a estabelecer a sua relação com o par que tem sido seu irmão, ou irmã, - (bio)lógico e político - ao longo da história, a noção de raça. Se os questionamentos feministas, somados aos questionamentos dos queer's studies, redundam, finalmente, na desnaturalização e desessencialização das definições e classificações humanas, $e$ se as duas definições $e$ classificações mais enraizadas na natureza, $e$ vistas como parte da essência humana, em nossa trajetória nesta terra são as de sexo $e$ raça, teríamos de chegar à discussão de sua relação. Talvez por isso os estudos sobre o corpo estejam se tornando tão evidentes na agenda dos estudos de gênero nesses últimos anos: é no corpo que essas marcas classificatórias são impressas. ${ }^{29}$

O que tudo isto tem a ver com a minha participação nessa pesquisa comparativa Portugal/Brasil? Acho que um resumo de uma possível resposta está no cartum em anexo..$^{30}$ Muitos anos

curso da "Fábrica de Idéias" da Universidade Cândido Mendes no ano passado. Ver RolAND, Edna. O movimento de mulheres negras brasileiras: desafios e perspectivas e SOARES, Vera. O verso e o reverso da construção da cidadania feminina, branca e negra, no Brasil, ambos na coletânea organizada por Guimarães, Antonio Sérgio Alfredo e HunTLEY, Lynn. Tirando a máscara. Ensaios sobre o racismo no Brasil. São Paulo, Paz e Terra, 2000.

${ }^{29}$ Outra vez, a antropologia tem uma contribuição a dar ao debate. Ver, por exemplo, a coletânea editada por LAMBECK, Michael e STRATHERN. Andrew Bodies and persons. Comparative perspectives from Africa and Melanésia. Cambride, Cambridge University Press, 1998. Ver também o número 14 de Cadernos Pagu; e STOLER, Ann Laura. Carnal knowledge and imperial power gender, race, and morality in Colonial Asia. In: LANCASTER, Roger N. $e$ LeONARDO, Micaela di. The gender/sexuality reader. Culture, History, Political Economy. NY e Londres, Routledge, 1997.

${ }^{30}$ Cartum de André Carrilho, publicado na Folha de S.Paulo de 6 de julho de 2000, parte da Mostra de Humor Luso-Brasileiro - 500 anos de Brasil, no Museu da Imagem e do Som do Rio de Janeiro. 
Do feminismo aos estudos de gênero

depois de Josephine Baker ter popularizado seu saiote de bananas no Folies-Bergère - e do derrière das negras africanas ter feito sucesso em Paris a partir do século 19 - Carmen Miranda deslocava as frutas tropicais, índice do exótico em outras terras, para seu turbante $e$, exibindo menos o corpo do que o fazia Josephine, ainda assim deixava à mostra uma outra zona de contato: uma nesga de barriga, definida como cor de café com leite na América do one drop rule, aliada ao tipo de música que levou para lá, bastou para racializá-la... Isto é, que estou supondo, como já disse em outras ocasiões ${ }^{31}$, que, além de terem em comum o fato de serem marcadores biologizados, naturalizados, historicamente, raça e sexo circulam como marcadores sociais, como cor e gênero, independentemente da definição de sexo ou de raça do corpo que os sustenta (Carmen Miranda era de origem portuguesa e, como todos sabem, era branca como um fantasma...). Aqui não é o lugar para desenvolver esta discussão; apenas a relembro para tentar responder à questão acima. Meu interesse por realizar esta comparação se prende, assim, tanto a uma interrogação teórica sobre a relação entre raça e gênero, como a meu interesse de pesquisa atual - que é a participação das mulheres na história da antropologia.

Um colega antropólogo, português, despertou minha curiosidade ao afirmar, numa de suas falas no Brasil, que em Portugal não tinha havido movimento feminista - afirmação que me foi depois reiterada por várias colegas, elas próprias trabalhando dentro do marco do feminismo. O que eu gostaria de descobrir nesta viagem é, então, primeiro, se, mesmo não tendo havido um "movimento" feminista em Portugal, houve uma contribuição das mulheres para a constituição da antropologia portuguesa? Para responder a esta pergunta preciso também descobrir como as mulheres eram vistas em Portugal $e$ nas

${ }^{31}$ Ver minha resenha de BouRdiEU, Pierre. La domination masculine. Paris, Seuil, 1998: O sexo da dominação. Novos Estudos (54), julho de 1999 e O mistério dos orixás e das bonecas: raça e gênero na antropologia brasileira. Etnográfica IV (2), 2000. 
colônias - e creio que aí (mas vocês me dirão se estou certa ou não) acho que a literatura pode ser uma boa porta de entrada para descobrir isso. Maria Archer e Margot Dias são, por enquanto, minhas únicas pistas. $\mathrm{E}$, claro, gostaria em segundo lugar de resolver o mistério da ausência do feminismo em Portugal. Numa entrevista recente, que Teresa teve a gentileza de me enviar, Maria Teresa Horta relembra os percalços de Novas cartas portuguesas e cita o Movimento de Libertação da Mulher, o julgamento do livro, a revista Mulheres, da qual era chefe de redação.... Enfim, dá pistas para se começar uma pesquisa. Mas a frase que mais me intrigou, e me levou a reler o livro foi a seguinte: "Mas não é um livro directamente feminista, é um livro sobre o que nós fazíamos em África, naquela altura...". ${ }^{32}$

\footnotetext{
32 [Pós-fácio: optei por manter o texto originalmente levado a Portugal para manter também seu caráter fragmentado e pessoal: não se tratava de uma pesquisa sobre a história da relação entre feminismo e gênero no país, mas de minha perspectiva parcial sobre esta relação. O texto documenta também um diálogo importante do Pagu com as colegas da Universidade Aberta, diálogo que todas temos de agradecer à iniciativa de Leila Algranti. Não fosse seu interesse, $e$ insistência, essa reflexão nunca teria sido feita... Deixo para um outro texto todas as descobertas interessantes que fiz lá sobre o feminismo em Portugal.]
} 
Do feminismo aos estudos de gênero

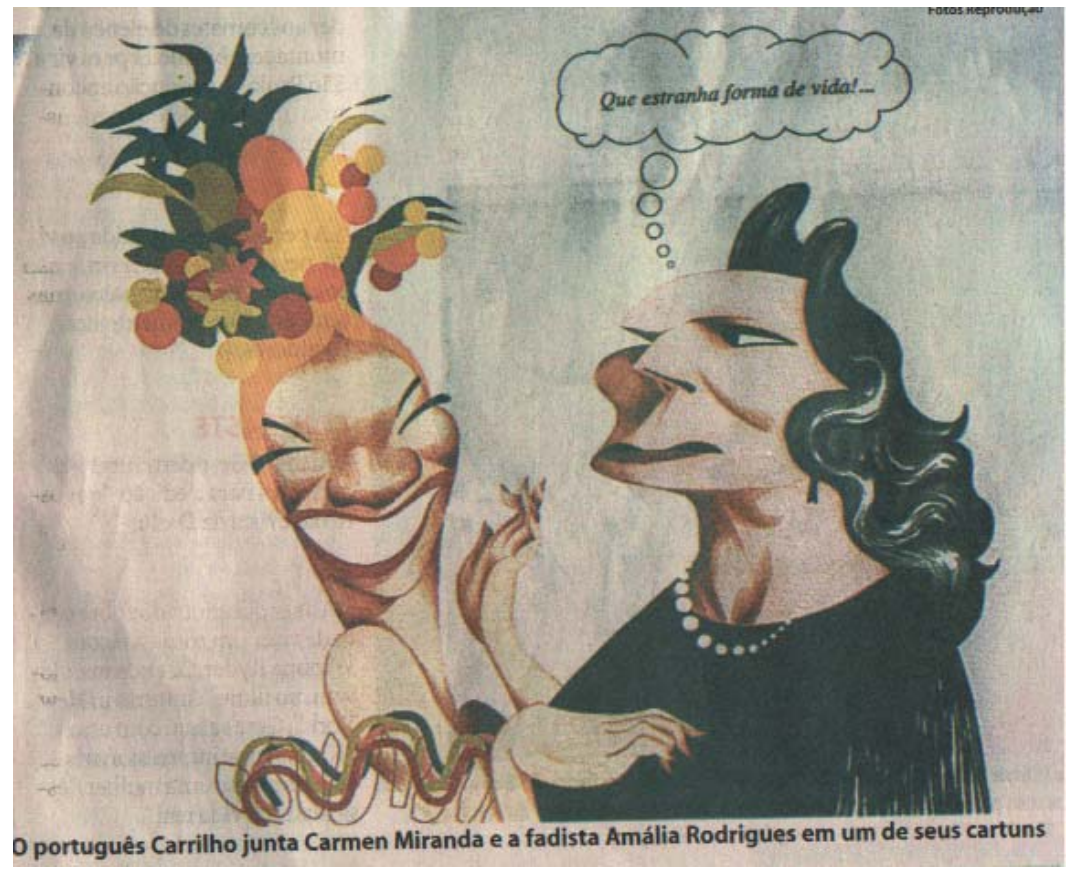

